\title{
EL COMPLEJO CÁRNICO URUGUAYO ANTE LA REALIDAD DEL MERCOSUR
}

POR

\author{
JOSÉ ANTONIO SEGRELLES SERRANO
}

\section{Introducción: antecedentes históricos}

Desde el punto de vista físico, la República Oriental del Uruguay constituye una transición entre la meseta brasileña y las llanuras pampeanas argentinas. El resultado es un relieve bastante uniforme, con suaves ondulaciones y altitudes máximas. denominadas «cuchillas» en el país, que apenas rebasan los 500 metros. La influencia moderadora del océano Atlántico y su situación latitudinal (entre $30^{\circ}$ y $35^{\circ}$ de latitud sur) propician un clima templado en el que las precipitaciones se distribuyen de forma regular a lo largar del año. Dichas características, unidas a la excelente calidad de los suelos, favorecen la existencia amplias praderas de gramíneas que han hecho de Uruguay un lugar privilegiado para la actividad ganadera extensiva desde los tiempos de la colonización española.

La riqueza natural de la denominada Banda Oriental fue objeto de disputas constantes entre España y Portugal en un primer momento, lucha que durante gran parte del siglo XIX cambió de contendientes, pues la frágil independencia uruguaya (1830) estuvo amenazada política y militarmente por Argentina y Brasil y económicamente por Gran Bretaña. A este respecto no falta quien asegura que el padrinazgo británico en la independencia uruguaya se debe a la necesidad que el imperio más poderoso de la época tenía de contar con una base de apoyo situada entre los dos países más grandes de América del Sur (Jacob, 1969).

José Antonio Segrelles Serrano. Dpto. de Geografía Humana. Universidad de Alicante.

Estudios Geográficos, LXIII, 246, 2002 
La principal motivación de estas naciones se relaciona en gran medida con el recurso fundamental del país: la ganadería. Antes de la independencia, a mediados del siglo XvIII se generalizan las incursiones de ciertos matarifes (changadores), muchas veces alentadas por el propio cabildo de Buenos Aires, destinadas a cazar ganado vacuno cimarrón para obtener el cuero, desaprovechando así la carne. Este producto, que contaba con un notable mercado en Gran Bretaña, era objeto de un intenso contrabando con Brasil.

En una segunda fase ya se utiliza la carne para abastecer a la numerosa mano de obra que trabajaba en las minas peruanas, las haciendas brasileñas y las explotaciones azucareras de las Antillas. De este modo se perfeccionan los métodos de conservación de las carnes mediante el secado (charqui) y el salado (tasajo).

Los intereses británicos aumentaron a partir de la independencia uruguaya y el tradicional mercado del cuero se extendió a la lana cuando en el primer tercio del siglo XIX introdujeron ovejas merinas en el país. Se puede decir, por lo tanto, que la economía de Uruguay era dependiente de Gran Bretaña si tenemos en cuenta las clásicas relaciones comerciales centro-periferia, ya que su función se limitaba a abastecer la industria inglesa de materias primas y, a su vez, importar productos manufacturados. Asimismo, en 1864 la Liebig Meat Extract Company abrió una fábrica en Fray Bentos, que muy pronto se convirtió en el principal complejo industrial de Uruguay, para elaborar los famosos cubitos de extracto de carne que se utilizaban en las sopas. En 1868, una compañía inglesa inició la construcción del primer ferrocarril que uniría Montevideo con el interior del país. También fueron empresarios británicos los que establecieron años más tarde (1902) el primer frigorífico uruguayo (Anglo), que empleaba el frío como método de conservación cárnica.

Tras las etapas de aprovechamiento casi exclusivo de los cueros y lanas, progresivamente va ganando terreno la explotación de las carnes. Con este fin se introducen en el primer tercio del siglo $\mathrm{xx}$ nuevas razas ovinas (Lincoln, Corriedale) y vacunas (Hereford, Aberdeen Angus, Shorton) de aptitud cárnica, que sustituyen a las poco productivas variedades criollas y se adaptan mejor a la demanda de los mercados.

Los orígenes agropecuarios de Uruguay siguen siendo una realidad de gran trascendencia en su economía. La participación del sector agropecuario en el Producto Interior Bruto (PIB) del país, aunque tien-

Estudios Geográficos, LXIII, 246, 2002

$$
-102-
$$


de a reducirse con el paso del tiempo, se sitúa alrededor del $12 \%$. Las exportaciones de productos básicos agrícolas, ganaderos y agroindustriales representan un promedio del $55 \%$ del total en el período 1990 1996, participación que alcanza el $80 \%$ si incluimos las exportaciones industriales de procedencia agropecuaria (calzado, artículos de cuero, confección de lana, papel) (Irigoyen, 1997).

En definitiva, el objetivo primordial del presente trabajo estriba en la exposición de las principales características de esta actividad tan vital para la economía uruguaya y aventurar las repercusiones que puedan derivar de su reciente integración regional. No obstante, conviene tener presente que el Mercosur es más un proyecto esperanzador que una realidad consolidada y, por lo tanto, las ideas aquí vertidas deben interpretarse como una aproximación prospectiva ante una integración político-económica que puede evolucionar de forma imprevisible.

\section{La industria frigorífica}

La industria frigorífica uruguaya se encuentra sustentada por una abundante y omnipresente ganadería extensiva de bovinos y ovinos. $\mathrm{El}$ censo vacuno se cifra en 10,7 millones de cabezas en 1996, mientras que el ovino asciende a 19,8 millones en la misma fecha. Ello significa que existen 3,4 vacas y 6,3 ovejas por habitante, coeficientes sólo superados en el mundo por Nueva Zelanda. Por el contrario, el ganado porcino es irrelevante dentro de la estructura pecuaria de Uruguay, pues en 1996 únicamente se censan 280.000 cabezas que suelen constituir un recurso complementario y de autoabastecimiento en las explotaciones agropecuarias.

La figura 1 constituye un fiel reflejo de esta realidad. El predominio de las plantas de sacrificio de bovinos y ovinos es manifiesto, ya que, bien individualmente, bien junto con otras especies, los primeros son faenados en 64 establecimientos y los segundos en 52, mientras que el ganado porcino lo es tan sólo en 19.

La localización departamental de los frigoríficos sigue un claro modelo mixto. Por un lado, se relaciona con las zonas pecuarias del centro y norte del país, pero por otro su ubicación tiene mucho que ver con la cercanía de los mercados consumidores del área costera meridional. Sólo los departamentos de Montevideo y Canelones concentran el 56,3\% 

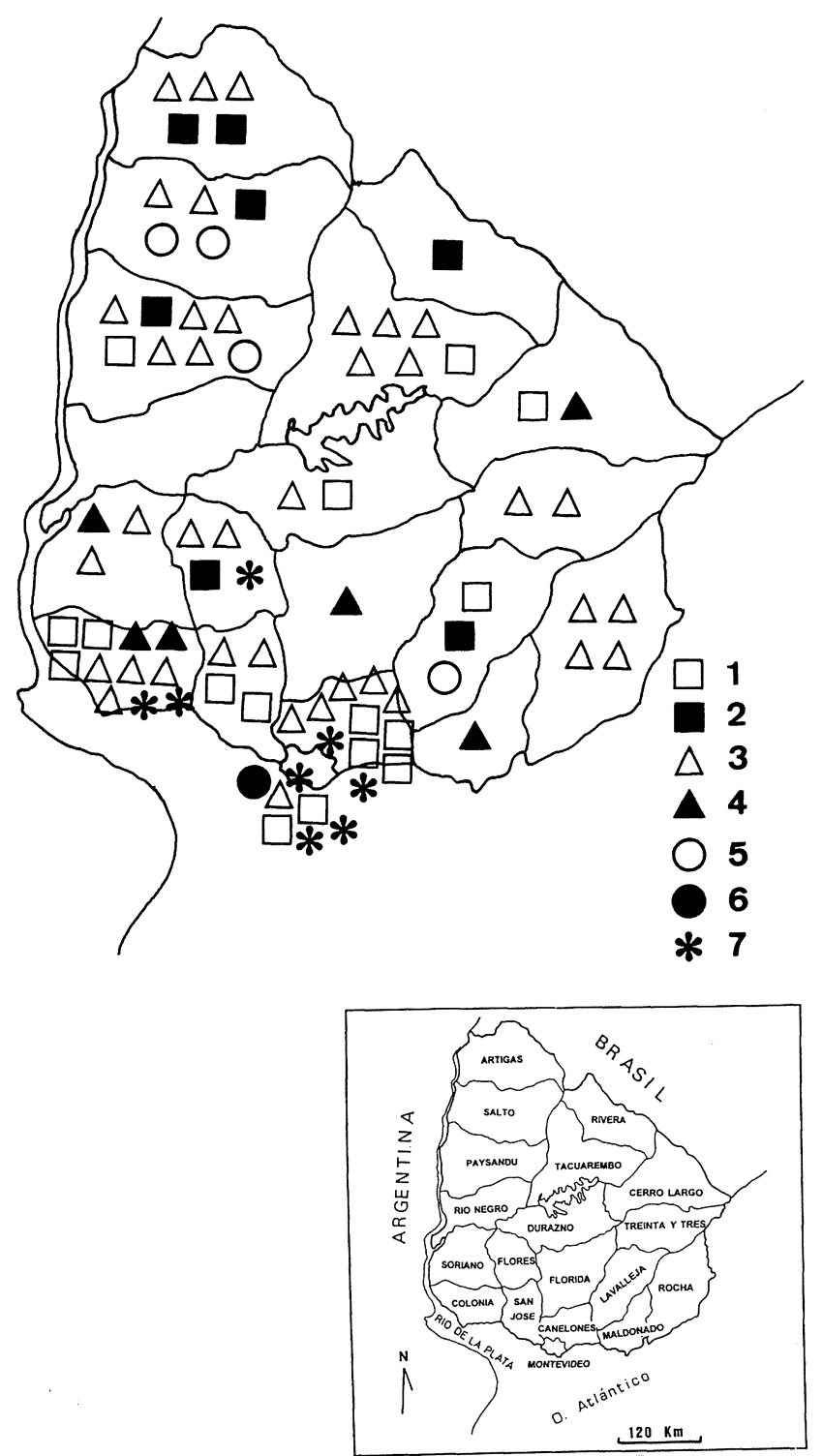

Fig. 1.-Localización departamental de los mataderos uruguayos según las especies ganaderas sacrificadas. Año 1997.

1, Bovino; 2, Ovino; 3, Bovino y ovino; 4, Bovino, ovino y porcino; 5 , Bovino y porcino; 6 , Ovino y porcino; 7 , Porcino.

Obs.: El mapa de la división departamental de Uruguay procede de PALAzón Ferrando,

S.: Los españoles en América Latina (1850-1990), Madrid, CEDEAL, 1995, p.21.

Estudios Geográficos, LXIII, 246, 2002

$$
-104-
$$


de la población total uruguaya, aunque este porcentaje se eleva hasta el $60,1 \%$ si añadimos el departamento de Colonia. Al mismo tiempo, aquí se encuentran los principales puntos de exportación cárnica, que se concretan en el activo puerto de Montevideo y en las zonas francas de Colonia, Nueva Palmira y Montevideo.

Los frigoríficos habilitados para el sacrificio de reses se distribuyen en cuatro categorías distintas que se relacionan con su radio de acción. Los que están autorizados para la exportación suponen el 30,0\% del total, incluyen únicamente a los ganados bovino y ovino y se localizan con preferencia en los departamentos de Montevideo, Canelones y Colonia (17,5\%). Los cinco primeros frigoríficos del país (cuatro en Canelones y uno en Tacuarembó) pertenecen a esta categoría y son los únicos que en 1996 superaron las 100.000 cabezas de ganado bovino sacrificadas, lo que supone el 44,8\% del total uruguayo. El grupo más abundante $(33,7 \%)$ está representado por los frigoríficos llamados nacionales, que como su propio nombre indica tienen una influencia territorial que abarca el conjunto del país. Aquí se ubica casi la totalidad de los mataderos de ganado porcino censados en Uruguay. Sin embargo, también existen numerosos establecimientos autorizados para servir sólo a los mercados departamentales (6,3\%) y locales (30,0\%). Estos dos últimos tipos predominan en los departamentos centrales y septentrionales y su número no se corresponde con las modestas producciones obtenidas.

La producción y el consumo cárnicos.-En el año 1996 se sacrificaron más de 1,8 millones de cabezas de ganado bovino y de 2,3 millones de ovino, lo que supone respecto a 1986 un incremento del 14,9\% y del 10,9\%, respectivamente. Este crecimiento se debe a tres razones básicas:

a) El proceso de erradicación de la fiebre aftosa, que genera buenas expectativas en los productores

b) La acentuación de medidas liberalizadoras tendentes, entre otras direcciones, a la eliminación de los stocks reguladores.

c) La mejora tecnológica y su abaratamiento relativo.

La situación es bien distinta para la ganadería intensiva. El número de cerdos sacrificados no ha dejado de disminuir durante las últimas décadas, cifrándose en 284.000 cabezas en 1996. Sin embargo, la avicultura 
de carne, aunque no alcanza la importancia de los aprovechamientos extensivos, experimenta un desarrollo reciente notable, ya que dicha producción aumentó un 100\% al pasar de 19.000 toneladas en 1986 a 38.000 en 1996. Este crecimiento de la avicultura de carne uruguaya se debe a los aportes de capital extranjero y a la generalización de la actividad integrada de forma vertical.

Por su parte, la demanda cárnica en Uruguay es causa y consecuencia del tipo de ganadería imperante tradicionalmente. Los uruguayos consumieron 98 kilogramos de carne por persona en 1996, lo que les sitúa en uno de los primeros puestos del mundo. Este consumo se distribuye de forma un tanto desequilibrada entre las especies pecuarias siguientes: 65 kilogramos de carne bovina, 15 de ovina, 12 de ave y 6 de porcina. Es decir, se trata de una estructura consuntiva contraria a la que predomina en España y la Unión Europea.

Pese a que la población uruguaya sigue manteniendo una clara preferencia por la carne bovina, la tendencia es levemente decreciente. Según los datos del Instituto Nacional de Carnes, durante los últimos veinte años ha disminuido de forma moderada el consumo de carne bovina y porcina, mientras que el de las carnes ovina y avícola tiende a incrementar su participación en la demanda de los consumidores como consecuencia de los profundos cambios que se están operando desde algunos años en los hábitos de consumo, tanto por lo que respecta a los propios productos como a la forma de adquirirlos y a la elección de los puntos de venta. En el caso concreto de la carne de pollo, el aumento del consumo, respaldado por una fuerte mercadotécnica, se relaciona con la generalización de nuevos productos avícolas más sofisticados (cortes, preparados, embutidos, etc.) que han tenido gran aceptación entre los clientes. Se prevé a corto plazo, además, un aumento de la demanda porque estos productos se expenden en establecimientos ubicados en sectores urbanos de alto nivel de renta (Ruiz, 1997).

Asimismo, el consumo de carne de cerdo resulta muy bajo para lo que es normal en otras partes del mundo debido a la escasa importancia de este aprovechamiento ganadero y a su elevado precio. Desde diversas instancias públicas y privadas se está intentando fomentar el consumo de la carne porcina fresca con el objeto de que una disminución en la demanda interna de carne bovina y un aumento de la porcina supondría la obtención de una mayor oferta para la exportación de carnes vacunas, que como es sabido gozan de gran reputación en los mercados exterio-

Estudios Geográficos, LXIII, 246, 2002

$$
-106-
$$


res por su calidad y producción natural. Para ello han surgido durante el último lustro granjas con elevado nivel tecnológico y vinculadas a la industria transformadora, que intentan aprovechar las ventajas comparativas, sobre todo de tipo sanitario, que Uruguay ofrece frente a sus competidores regionales.

El comercio exterior de productos cárnicos. - La ganadería uruguaya está completamente volcada hacia los mercados exteriores, siendo desde siempre exportadora neta de carnes bovinas y ovinas. Los productos cárnicos en general, con 335,5 millones de dólares, representan el $14 \%$ del valor total de las exportaciones realizadas por el país en 1996 y superan a los cueros y lanas que suponen el $11,5 \%$ en la misma fecha.

De las figuras 2 y 3 se desprende que los principales mercados de las carnes uruguayas más representativas radican en la Unión Europea (UE) y en el propio Mercosur. La participación europea en las exportaciones cárnicas de Uruguay es mucho más acusada si tenemos en cuenta el valor monetario ( $59 \%$ en ovino y $34 \%$ en bovino) que si consideramos el peso en canal ( $44 \%$ en ovino y $25 \%$ en bovino), ya que el mercado europeo es el destinatario de los despieces más valiosos. Sin embargo, con el Mercosur sucede lo contrario, pues su representatividad aumenta en el volumen de las importaciones y disminuye en la cuantía económica de las mismas.

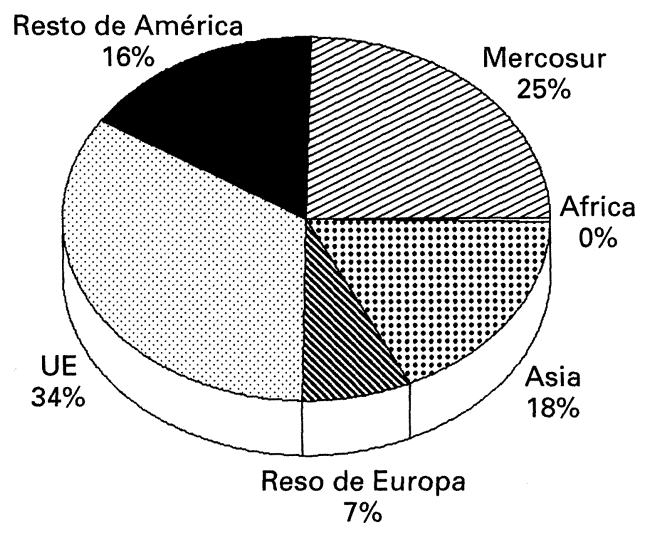

Fig. 2.-Valor de las exportaciones uruguayas de carne bovina por áreas de destino. Año 1996.

Estudios Geográficos, LXIII, 246, 2002 


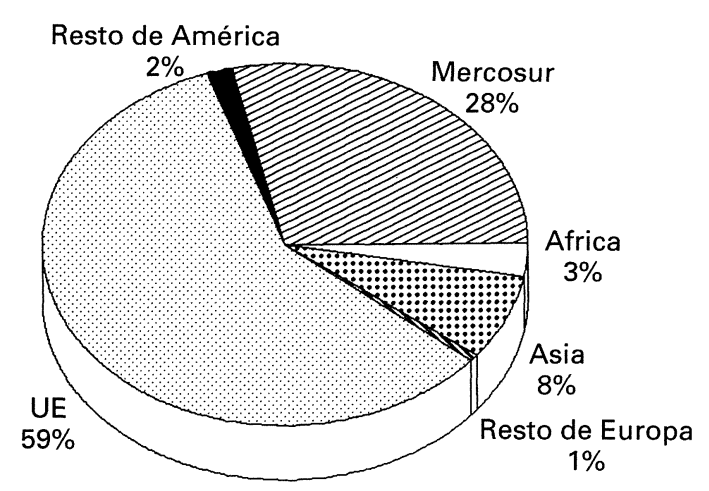

FIG. 3.-Valor de las exportaciones uruguayas de carne ovina por áreas de destino. Año 1996.

A pesar de la profunda disminución de la demanda de carne vacuna que se produjo en el mercado comunitario como consecuencia de la detección de la Encefalopatía Espongiforme Bovina (BSE) en la cabaña británica a partir de marzo de 1996, las exportaciones uruguayas de este producto a la UE aumentaron un 6,9\% respecto al año anterior, lo que demuestra la confianza de los consumidores europeos en la calidad y las condiciones higiénico-sanitarias de las carnes bovinas de Uruguay.

El destino prioritario en 1996 para la carne bovina uruguaya en la UE radica en el Reino Unido (38,4\%), seguido de Alemania (26,2\%), Países Bajos (12,3\%) e Italia (10,0\%). En el caso del Mercosur, el principal comprador es Brasil con el 74,8\%. A continuación figura Chile, en calidad de país asociado a este bloque económico, con el 15,0\%. En Asia es Israel el lugar que aparece en la cabeza (90,3\%), mientras que en el resto de América el grueso de las exportaciones las absorbe Estados Unidos (90,2\%). Egipto, por su parte. concentra el $79,3 \%$ del total africano. Respecto a las carnes ovinas, el primer comprador europeo es Alemania (48,7\%). Después figuran el Reino Unido $(16,0 \%)$ y los Países Bajos $(14,0 \%)$. En el Mercosur destaca Brasil (72,6\%), Perú en el resto de América (46,5 \%), Israel en Asia (58,7\%) y Argelia en África (84\%)

Uruguay goza de una nueva situación sanitaria al ser reconocido, tras varias décadas de peticiones infructuosas, como país libre de fiebre aftosa sin vacunación por el Departamento de Agricultura de Estados Unidos (USDA) en noviembre de 1995 y por la Organización Interna- 
cional de Epizootias (OIE) en mayo de 1996. Diversos problemas de seguridad alimentaria a escala mundial (BSE, E.coli, etc.) aceleraron sin duda este reconocimiento, lo cual supone para las carnes uruguayas la posibilidad de acceder a una serie de nuevos mercados que se caracterizan bien por tener una demanda creciente, como México, bien por su tradicional exigencia en cuanto a la calidad de los productos alimentarios importados, como sucede con Japón.

En el caso mexicano, la carne vacuna refrigerada uruguaya deberá competir con la de Estados Unidos, cuyo ingreso no está sujeto al pago de aranceles. El arancel fijado para Uruguay, sin embargo, es del 13\%, es decir, menor que el que se aplica a las carnes de otras procedencias, que oscila entre el $20 \%$ y el $25 \%$. La competencia por el mercado japonés se establece con los proveedores tradicionales (Estados Unidos, Australia, Nueva Zelanda), que cuentan con ventajas comparativas derivadas de su larga experiencia y de su proximidad geográfica, las carnes uruguayas ya están haciendo valer sus garantías sanitarias y su producción natural, libre de aditivos químicos.

Otros mercados emergentes que constituyen un objetivo prioritario para la industria frigorífica de Uruguay se encuentran en Rusia, algunos países de Europa Central y Oriental, China, Taiwán y Corea del Sur, así como Granada, Jamaica, Trinidad-Tobago, Barbados y Bahamas, pues la intensa actividad turística de estos enclaves caribeños requiere un abastecimiento cárnico de elevada calidad.

Desde el año 1996, el Instituto Nacional de Carnes estableció un nuevo sistema de clasificación y tipificación de las carnes con el fín de ajustarse a la demanda y obtener precios más atractivos en mercados tan exigentes como los señalados, toda vez que la calidad de un producto guarda estrecha relación con una correcta y transparente tipificación.

\section{La integración del complejo cárnico uruguayo en el Mercosur}

La progresiva globalización de la economía y la creciente liberalización comercial, auspiciada por los recientes acuerdos del GATT (Acuerdo General sobre Tarifas Aduaneras y Comercio), plantean la necesidad de llevar a cabo proyectos de integración regional para afrontar los nuevos retos que se avecinan. La formación de dilatados espacios económicos puede permitir una adecuada inserción en los grandes flu- 
jos del comercio mundial. Una de estas integraciones regionales está constituida por el llamado Mercado Común del Sur (Mercosur), conformado por Argentina, Brasil, Paraguay y Uruguay, que firmaron en marzo de 1991 el Tratado de Asunción. Más tarde se unieron Bolivia y Chile en calidad de asociados. Esta unión regional latinoamericana permitiría no sólo mejorar las relaciones comerciales, productivas y políticas entre los países miembros, sino también generar una mayor capacidad de negociación con el resto del mundo de la que es posible lograr a cada país por separado (Alonso et al., 1996).

Desde el punto de vista social y económico, el Tratado de Asunción contempla la libre movilidad de bienes, servicios y factores productivos, la fijación de un arancel externo común y la adopción de políticas en el terreno macroeconómico y en la actuación sectorial en áreas como las siguientes: agropecuaria, industrial, de servicios, transportes y comunicaciones, cambiaria y de capital, monetaria, fiscal y aduanera.

La coordinación regional de estas políticas puede ser especialmente beneficiosa para el sector cárnico de los países del Mercosur, ya que se trata de una actividad tradicional que todavía en la actualidad goza de un peso específico fundamental en sus economías. Además de la relativa complementariedad que ofrece la producción cárnica de los países miembros, que supone una competencia regional algo suavizada, el futuro resulta prometedor una vez que se cumplan los acuerdos del GATT de forma rigurosa. La eliminación de los subsidios a la exportación en la UE reducirá la presencia de los productos cárnicos europeos en el Mercosur, al mismo tiempo que la progresiva apertura del mercado comunitario incrementará las posibilidades comerciales de estos países latinoamericanos en Europa.

La complementariedad de la producción de carne en los países del Mercosur se basa en el carácter de exportadores netos de carnes bovinas que ofrecen Argentina y Uruguay, mientras que Brasil es un gran productor de carne porcina y avícola a la vez que necesita importar grandes cantidades de carne vacuna para satisfacer las necesidades de su mercado interno. Pese a esta realidad, el complejo cárnico uruguayo tendrá ante sí la nada fácil tarea de hacer valer sus ventajas comparativas frente a los dos gigantes económicos de la región.

EI subsector bovino de carne.-La carne de bovino es el producto cárnico tradicional en los países Mercosur. La cabaña regional asciende

Estudios Geográficos, LXIII, 246, 2002

$$
-110-
$$


a 230,8 millones de cabezas en 1996, de los que Brasil concentra el $68,9 \%$, Argentina el $23 \%$, Uruguay el $4,6 \%$ y Paraguay el $3,5 \%$. Sin embargo, la productividad brasileña de este sub sector es más baja que la argentina o la uruguaya porque la producción está sometida a marcadas variaciones estacionales y los problemas sanitarios en el ganado vacuno distan de estar solucionados.

El consumo de carne de vacuno también es dispar en la región. Mientras Uruguay y Argentina alcanzan un consumo anual por persona de 65 y 57 kilogramos, respectivamente, Paraguay apenas rebasa los 41 kilogramos y Brasil no llega a los 30 . En el caso argentino, el consumo de carnes bovinas se encuentra estrechamente relacionado con el comportamiento de las exportaciones, de forma que cuando las ventas en el exterior descienden es el mercado interno el que absorbe gran parte de la producción. En Brasil, las exportaciones dependen de las fluctuaciones de la producción y el consumo, aunque no se puede obviar que las grandes necesidades de su mercado interno absorben sobre el $95 \%$ de la producción. Los períodos de estabilidad monetaria, auspiciados por el Plan Cruzado (1986) y el Plan Real (1994) han provocado un crecimiento de la demanda como consecuencia del aumento del poder adquisitivo de las clases medias brasileñas.

El mantenimiento de la estabilidad económica de Brasil deviene trascendental para las perspectivas del subsector bovino uruguayo, pues a medio y largo plazo el mercado brasileño debe convertirse en un objetivo prioritario para las carnes vacunas de Uruguay. Sólo un aumento de uno o dos kilogramos de carne bovina consumida por cada habitante de los 161,5 millones que censa Brasil puede significar un vuelco sin precedentes para el escaso comercio de este producto que en la actualidad existe entre los países del Mercosur, sobre todo si se compara con la producción total de la región.

El comercio regional de carnes bovinas está libre de trabas aduaneras excepto en el caso de Paraguay, que ha colocado este producto en la lista de excepciones y aplica aranceles para la importación que oscilan entre el $29,5 \%$ y el $34,5 \%$ (Verheijden, Verheijden, 1997). La desprotección arancelaria obligará a las carnes vacunas uruguayas a competir no sólo con las producciones de países terceros, sino también con las de sus propios socios en el Mercosur. La principal ventaja comparativa de Uruguay, como ya se ha comentado, estriba en las excelentes condiciones higiénico-sanitarias de su cabaña, sobre todo si tenemos en 
cuenta que la fiebre aftosa, que constituye un grave problema en Brasil, sólo está siendo controlada recientemente en Argentina.

En cualquier caso, las perspectivas inmediatas apuntan hacia la consolidación de Argentina y Uruguay como exportadores netos de carne bovina, mientras que Brasil, pese a exportar en ocasiones cantidades notables y ser un gran productor, se verá obligado a importar este producto desde sus vecinos regionales, tanto para satisfacer la creciente demanda interna con cortes de elevada calidad como para abastecer su industria procesadora de carnes y más tarde reexportarlas a otros mercados exteriores.

El subsector avícola de carne.-Los principales productores de carne de pollo en el Mercosur son Brasil (3,8 millones de toneladas en 1995) y Argentina (690.000 toneladas en 1995), mientras que Uruguay sólo produce 38.000 toneladas en la misma fecha. Estas grandes diferencias son extensivas al consumo, pues en 1995 los 12 kilogramos por habitante de Uruguay resulta una cifra muy baja comparada con la de Argentina (21 kilogramos) y Brasil (23 kilogramos). Pese a estas disparidades, en todos los países del Mercosur ha habido un rápido crecimiento del consumo de carne de pollo durante los últimos años, ya que en 1986 en Uruguay se consumían 5,1 kilogramos por habitante, en Argentina 10 kilogramos en 1989 y en Brasil 2,4 kilogramos en 1970. La razón de este aumento es doble. En primer lugar, la carne de pollo ha ganado popularidad en todo el mundo frente a las carnes vacunas porque se considera un producto sano, fácil de preparar y relativamente barato. En segundo lugar, se debe considerar que ciertos países, como Brasil o Chile, están experimentando desde hace varios años un crecimiento sostenido en su Producto Interior Bruto (PIB). Como en ellos abundan los habitantes con rentas bajas, cuando el poder adquisitivo de éstos comienza a crecer una gran parte de los ingresos familiares se destina a la alimentación. El precio asequible de la carne de pollo provoca que sea el consumo de este producto el primero que aumenta en este tipo de situaciones.

El subsector avícola de carne ha alcanzado en Brasil un desarrollo sobresaliente que lo convierte en el segundo exportador del mundo y en el principal productor regional. Esta supremacía se debe al fuerte grado de integración vertical y horizontal existente y al elevado nivel tecnológico y genético conseguido. Las cinco empresas más grandes (Sa-

Estudios Geográficos, LXIII, 246, 2002

$$
-112-
$$


dia, Perdigao, Frangosul, Ceval/Agroeliane y Avipal), que se localizan preferentemente en los estados meridionales de Santa Catarina y Río Grande do Sul, absorben el 35\% de la cuota de mercado. Estas compañías no sólo controlan la producción de pollos y la fabricación de piensos compuestos, sino también la transformación y comercialización de los productos. Su ubicación en las principales áreas productoras de maíz y soja les permite abaratar los costes de producción, lo que las hace muy competitivas a nivel internacional.

La producción argentina de carne de pollo es menos eficaz que la brasileña, aunque posee un potencial notable derivado de la abundante disponibilidad de soja y maíz. No obstante, Argentina es eminentemente importadora de este producto, siendo Brasil el proveedor fundamental con 19.000 toneladas en 1995, es decir, el 96,9\% del total importado.

En el caso uruguayo, este subsector, ante el ascenso de la demanda, se ha modernizado mucho mediante recientes inversiones en producción, incubación y avanzadas fábricas de piensos compuestos que posibilitan un nivel tecnológico similar al brasileño que. además, se ve apoyado por unas condiciones sanitarias idóneas. Este desarrollo avícola tiene como objetivo prioritario el abastecimiento del mercado interno, pero una vez satisfechas sus necesidades suele haber excedentes, a veces muy pequeños, que se destinan a la exportación, fundamentalmente a Argentina. En 1990 se vendió en el exterior el 12,6\% de la producción, mientras que en 1995, debido al aumento del consumo, este porcentaje fue sólo del 4,6\% pese al crecimiento de la carne obtenida.

Asimismo, mientras en los mercados brasileño y argentino los precios del pollo son muy variables (hasta un $50 \%$ en períodos muy cortos), fundamentalmente en situaciones de desfase cambiarlo, en Uruguay, por el contrario, presentan una gran estabilidad (Ruiz, 1997).

Sin embargo, Uruguay no tiene la misma facilidad que Argentina y Brasil para el aprovisionamiento de materias primas y debe pagar los precios más altos de la región por los insumos, lo que influye de manera directa en los costes de producción. La permanencia de estas condiciones acabarían por comprometer la competitividad del subsector y descartar cualquier intento de exportar a la región.

El subsector porcino.-La carne de cerdo es muy poco representativa en los países del Mercosur, el principal productor es Brasil (1,4 millones de toneladas en 1995). Aunque el consumo de productos deriva- 
dos está ganando amplia aceptación en la región, la carne fresca tiene mala imagen debido a la existencia de recientes problemas sanitarios, no se considera tan sabrosa como la de vacuno y es más cara que la de pollo. Brasil arroja un consumo anual por habitante de 8 kilogramos en 1995, 6,7 Argentina, 6 Uruguay y 11,2 Chile, que es el más elevado del Cono Sur. A este respecto, es previsible que el crecimiento económico de la región lleve consigo un aumento de la demanda de este producto en los próximos años.

La actividad porcina brasileña tiene una estructura similar a la del subsector avícola de carne, es decir, está muy tecnificada y posee un alto grado de integración vertical en su cadena productiva, tanto hacia arriba (piensos compuestos) como hacia abajo (distribución). Casi el 80\% de los productores del estado de Santa Catarina se encuentran integrados a los potentes grupos Sadia, Seará, Chapecó y Perdigao (Ruiz, 1996). Del mismo modo que sucede con la avicultura, la expansión de la producción porcina se debe al desarrollo del maíz y las oleaginosas del área meridional del país, base principal para la elaboración de piensos.

El subsector porcino en Argentina se encuentra poco desarrollado y con escaso grado de tecnificación pese a la abundante disponibilidad de granos. La integración vertical no es significativa, aunque durante los últimos años han surgido empresas pujantes de capital extranjero (Brasil, Estados Unidos, España) que incorporan tecnología avanzada y genética, invierten en el proceso industrial y comienzan a controlar la distribución. Alrededor del 80\% del ganado porcino argentino se cría al aire libre con métodos extensivos. Este sistema de producción ofrece índices productivos similares a los de las explotaciones en estabulación, costes de producción más bajos, inversiones menos onerosas y mayor integración con el medio natural (Ambrogi, Migues, 1997).

El aprovechamiento porcino constituye un recurso complementario y de autoabastecimiento en las explotaciones agropecuarias uruguayas. Los animales son alimentados con los desechos agrícolas disponibles, que ofrecen escaso valor nutritivo. Aunque son muy escasas las explotaciones especializadas, en los años más recientes también han surgido aquí granjas con elevado nivel tecnológico y vinculadas a la industria transformadora. Un ejemplo digno de mención es el de Pig Uruguay, S.A. (Pigusa), proyecto iniciado en 1993 y que tras una inversión de $30 \mathrm{mi}$ llones de dólares cuenta con una base productiva de 4.000 cerdas y un sacrificio anual cercano a los 100.000 animales. Esta empresa integrada

Estudios Geográficos, LXIII, 246, 2002 
verticalmente pretende mejorar la imagen de la carne de cerdo en el país, satisfacer la demanda interna y fortalecer las exportaciones hacia sus vecinos regionales en la medida de lo posible.

Esta última cuestión es importante porque hasta ahora el principal flujo comercial de carnes porcinas del Mercosur está constituido por las exportaciones de Brasil a Argentina, las cuales representan el 55\% de las importaciones totales del país rioplatense. No obstante, los problemas zoosanitarios brasileños hacen que sólo puedan entrar en el mercado argentino las carnes procedentes de los estados de Santa Catarina y Río Grande do Sul. La prohibición de Uruguay, sin embargo, es total y afecta a todo el país.

Tanto los flujos mercantiles existentes en la región como las pésimas garantías sanitarias de Brasil suponen una ventaja comparativa que el subsector porcino uruguayo puede aprovechar a medio plazo, ya que, en primer lugar, la cercanía del mercado argentino abarata los fletes y, en segundo lugar, la proximidad al Río de la Plata representa un valor añadido notable, pues los vientos dominantes, que tienen una componente sur y suroeste, proceden del mar y protegen al país del contagio de enfermedades de transmisión aérea, es decir, se evita así un problema que es reconocido como vital en todos los criaderos porcinos del mundo.

\section{Conclusiones}

Dentro del sector agropecuario uruguayo, que representa el 12\% del PIB,destaca ante todo la ganadería de aptitud cárnica y, por extensión, la industria frigorífica, actividad que de forma tradicional ha supuesto la principal fuente de ingresos del país al tratarse de una economía de rasgos monoproductores y netamente exportadora de carne.

El crecimiento de la producción, el aumento de la productividad, la constante mejora tecnológica, las crecientes inversiones y las garantías higiénico-sanitarias permiten augurar una expansión continua para el complejo cárnico de Uruguay, si bien deben arbitrarse diversas estrategias, como el fortalecimiento de la integración entre la producción y la industria, la constancia en la oferta de materia prima, el desarrollo de nuevos productos o la promoción de los mismos, para no hipotecar el futuro de las cadenas agroindustriales de la carne.

Estudios Geográficos, LXIII, 246, 2002

$$
-115-
$$


ABstRACT: The agricultural origins of Uruguay are still a highly important factor in its present economy, although meat agrocomplex has a special weight concerning both production and foreign trade.

The Uruguay meat agrocomplex will have to face progressive globalization of the economy and growing free trade around the world. Regional integration in Mercosur will be an efficient instrument to entrance the comparative advantages of the different livestock subsectors. However, we should not forget the repercussions that proceed from economic power, competitivity and political, monetary and financial stability of Argentina and Brazil.

KEY WORDS: Meat agrocomplex, Uruguay, Mercosur.

RÉsumé: Les origines du complexe agricole et de l'élevage représente encore aujourd'hui une réalité vitale pour son économia actuelle même si c'est surtout l'industrie de la vianda celle qui se détache aussi bien par sa production que par son commerce extérieur.

Les industries de la viande à Uruguay doit affronter la progressive globalisation de l'économie et la libéralisation commerciale toujours croissante dans le monde. Leur intégration régionale dans Mercosur peut étre un instrument éfficace pour la mi se eu reliéf des avantages des différents sous-secteurs de l'élevage et la comparaison entre eux. Par contre, il fandrait ne pus oublier les répercussions dérivées du poids économique, la libre concurrence et la stabilité politique, monétaire et financière de l'Argentine et du Brésil.

Mots CLÉs: Les industries de la viande, Uruguay, Mercosur. 
el Ministerio de Ganadería, Agricultura y Pesca uruguayo, que se encaminaría hacia una especialización regional en la producción de carne vacuna por la que Uruguay se dedicaría preferentemente a la cría y Argentina al engorde de las reses. Si esta perspectiva llegara a culminar no tardarían en dejarse sentir sus efectos negativos sobre el agro uruguayo, en general, y el complejo cárnico, en particular, ya que el abandono de praderas y el cierre de frigoríficos sería una consecuencia directa de la disminución del valor añadido de la producción nacional y el retraimiento de una demanda industrial muy concentrada y ubicada en el exterior.

\section{BIBLIOGRAFÍA}

Alonso, J. M., et al.: Se nos vino el Mercosur. Los trabajadores en el proceso de integración, Montevideo, Fundación Friedrich Ebert (FESUR)-Centro Interdisciplinario de Estudios sobre el Desarrollo, Uruguay (CIEDUR), 1996, $184 \mathrm{pp}$.

Ambrogi, A., Miguez, M.: «Mercosur y ganado porcino: perspectivas», en C. BuXadé CARBó (coord.): Producción porcina: aspectos claves, Madrid, Mundi-Prensa, 1997, pp. 57-73.

INAC, Anuario Estadistico de Existencias, Faena y Exportación '96, Montevideo, 1997, 95 pp.

IRIGOYEN, R. M.: «La incógnita agropecuaria», Agora. Finanzas \& Agronegocios, n. ${ }^{\circ} 1$, julio 1997, Montevideo, pp. 18-20.

JACOB, R.: Consecuencias sociales del alambramiento (1872-1880), Montevideo, Ediciones de la Banda Oriental, 1969, $120 \mathrm{pp}$.

RUIZ, M. I.: «Caracterización del sector porcino», Anuario '95, Montevideo, Oficina de Programación y Política Agropecuaria (Ministerio de Ganadería, Agricultura y Pesca), 1996, pp. 89-98.

RuIz, M. I.: «Avicultura: situación y perspectivas», Anuario '96, Montevideo, Oficina de Programación y Política Agropecuaria (Ministerio de Ganadería, Agricultura y Pesca), 1997, pp. 83-89.

VerheiJden, S. M., VerheiJden, M. W.: The impact of MERCOSUR on Southern Cone agribasiness, Utrecht, Rabobank International, 1997, 88 pp.

RESUMEN: Los orígenes agropecuarios de Uruguay continúan representando una realidad trascendental en su economía actual, aunque ante todo destaca el complejo cárnico, tanto por lo que respecta a la producción como al comercio exterior.

El complejo cárnico uruguayo va a tener que hacer frente a la progresiva globalización de la economía y a la creciente liberalización comercial en el mundo. Su integración regional en el Mercosur puede ser un instrumento eficaz para resaltar las ventajas comparativas de sus distintos subsectores ganaderos. Sin embargo, no conviene olvidar las repercusiones que deriven del peso económico, posible competencia y estabilidad política, monetaria y financiera de Argentina y Brasil.

Palabras Clave: Complejo cárnico, Uruguay, Mercosur.

Estudios Geográficos, LXIII, 246, 2002 
ABSTRACT: The agricultural origins of Uruguay are still a highly important factor in its present economy, although meat agrocomplex has a special weight concerning both production and foreign trade.

The Uruguay meat agrocomplex will have to face progressive globalization of the economy and growing free trade around the world. Regional integration in Mercosur will be an efficient instrument to entrance the comparative advantages of the different livestock subsectors. However, we should not forget the repercussions that proceed from economic power, competitivity and political, monetary and financial stability of Argentina and Brazil.

KEY WORDS: Meat agrocomplex, Uruguay, Mercosur.

RÉSUMÉ: Les origines du complexe agricole et de l'élevage représente encore aujourd'hui une réalité vitale pour son économia actuelle même si c'est surtout l'industrie de la vianda celle qui se détache aussi bien par sa production que par son commerce extérieur.

Les industries de la viande à Uruguay doit affronter la progressive globalisation de l'économie et la libéralisation commerciale toujours croissante dans le monde. Leur intégration régionale dans Mercosur peut étre un instrument éfficace pour la mi se eu reliéf des avantages des différents sous-secteurs de l'élevage et la comparaison entre eux. Par contre, il fandrait ne pus oublier les répercussions dérivées du poids économique, la libre concurrence et la stabilité politique, monétaire et financière de l'Argentine et du Brésil.

Mots CLÉs: Les industries de la viande, Uruguay, Mercosur. 